\title{
ELECTROLYZER EXERGY ANALYSIS FOR AN ENVIRONMENTAL CONTROL AND LIFE SUPPORT SYSTEM
}

\author{
Raymond Chow \\ University of Alabama in \\ Huntsville \\ Huntsville, Alabama, 35899
}

\author{
George J. Nelson \\ University of Alabama in \\ Huntsville \\ Huntsville, Alabama, 35899
}

\author{
Jay L. Perry \\ NASA, George C. Marshall \\ Space Flight Center \\ Huntsville, Alabama, 35812
}

\begin{abstract}
An exergy based analysis of the Environmental Control and Life Support System (ECLSS) aboard the International Space Station (ISS) is conducted to assess its overall performance. Exergy is chosen as a measure of performance because it accounts for both the first and second laws of thermodynamics. The exergy efficiency of a system is first defined as the total exergy destroyed by the system relative to the total exergy input to the system. To determine the ECLSS exergy efficiency, the system is divided into constituent subsystems which in turn are divided into assemblies and components. Based on this system decomposition, exergy balances are derived for each assembly or component. Exergy balances and supporting calculations are implemented in MATLAB ${ }^{\circledR}$ code. The major subsystems of the ECLSS considered in this analysis include the Atmosphere Revitalization Subsystem (ARS), Atmosphere Control and Supply Subsystem (ACS), Temperature and Humidity Control Subsystem (THC), Water Recovery and Management Subsystem (WRM), and Waste Management Subsystem (WM). This paper focuses on the ARS and its constituent assemblies and components. Exergy efficiency of the ARS and its constituent assemblies and components is first presented. The Oxygen Generation Assembly (OGA), an assembly within the ARS, is then highlighted because the exergy destruction by the OGA is a large magnitude contributor to the overall exergy destruction of the ECLSS. The OGA produces oxygen to meet the crew's metabolic demand via water electrolysis in a proton exchange membrane (PEM) electrolyzer. The exergy destruction of the OGA's PEM electrolyzer is a function of the amount of oxygen produced, which determines the necessary current density and voltage drop across the PEM electrolyzer. In addition, oxygen production in the PEM electrolyzer requires deviation from the Nernst potential, presenting trade-offs between the exergy efficiency and critical life support functions. The results of parametric studies of PEM electrolyzer performance are presented with an emphasis on the impacts of polarization and operational conditions on exergy efficiency.
\end{abstract}

\section{INTRODUCTION}

The Environmental Control and Life Support System (ECLSS) executes vital functions that sustain the crew aboard the International Space Station (ISS) [1]. On a system level, the ECLSS is a complex component within the ISS's system of systems. The ECLSS is divided into multiple subsystems that each do very specific tasks. These subsystems include the Atmosphere Revitalization Subsystem (ARS), Atmosphere Control and Supply Subsystem (ACS), Temperature and Humidity Control Subsystem (THC), Water Recovery and Management Subsystem (WRM), and Waste Management Subsystem (WM). The ARS is particularly important because it maintains a habitable environment for the crew by supplying oxygen and purifying the cabin atmosphere by removing carbon dioxide $\left(\mathrm{CO}_{2}\right)$ and gaseous chemical contaminants.

Generating oxygen to meet crew metabolic demands is accomplished by the Oxygen Generation Assembly (OGA) via a water electrolysis process which consumes a large amount of power in order to separate water into molecular hydrogen and oxygen. Beyond this application aboard the ISS, water electrolysis is also used to generate hydrogen to be used by fuel cells that employ the reverse reaction to generate power.

Exergy is a measure of the work obtainable from a system. It is derived by combining the first and second laws of thermodynamics; therefore, exergy accounts for both the first law energy balance and second law entropy balance [2]. Irreversible processes result in the generation of entropy and attendant destruction of exergy. Therefore, one way to characterize the efficiency of a system is through exergetic efficiency. If less irreversibility occurs in a process it is more exergetically efficient because less exergy is destroyed and more obtainable work remains.

Previous studies have addressed exergy destruction and exergy efficiency of PEM electrolyzers [3-5], but those studies have focused on higher temperature PEM electrolyzers that are significantly different from the low temperature PEM 
electrolyzer used in the OGA. The previous studies found that increasing the operating temperature of the electrolyzer increases the exergy efficiency. In addition, the purpose of the electrolyzer in the ECLSS is to generate oxygen for the crew while the hydrogen produced is vented to space instead of being stored for later use in power production via fuel cells, as in other applications. Therefore, definitions of exergy efficiency for the OGA electrolyzer take a different form than in the previous studies to reflect the different purpose of the OGA electrolyzer.
There have also been numerical studies on other components of the ECLSS. An example is the Carbon Dioxide Removal Assembly (CDRA), for which studies have focused on transient modeling of transport processes and optimization of carbon dioxide $\left(\mathrm{CO}_{2}\right)$ removal processes [6,7]. Exergy analysis presents a means of integrating the physical behavior of these distinct subsystems, and findings from those studies could be incorporated into system level exergy models in future work.

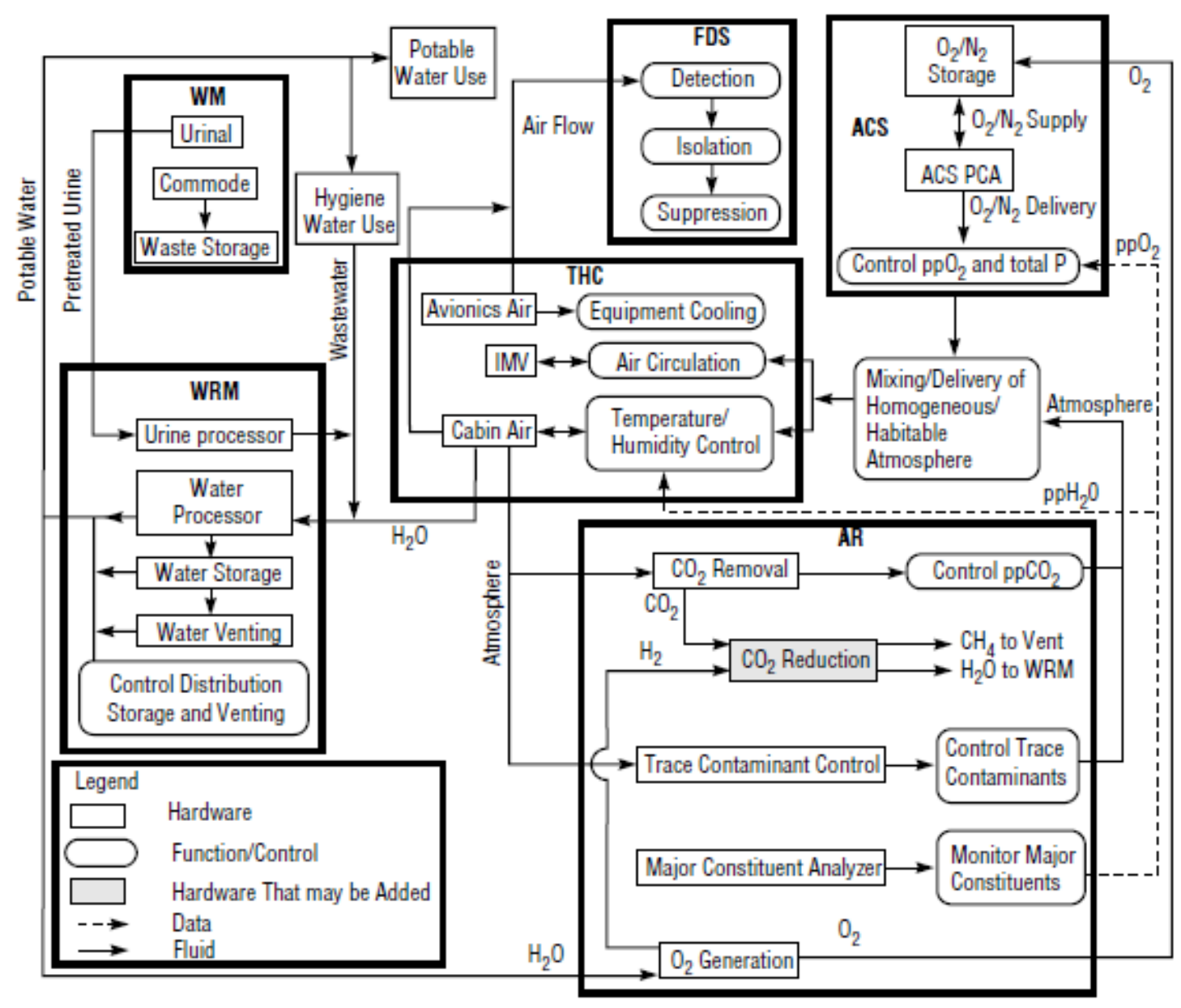

Figure 1. Schematic of the 1998 ISS ECLSS configuration.

In this paper an initial exergy analysis of the ISS ECLSS is presented based upon publicly available data on the configuration documented in 1998 and shown by Figure 1 [1]. This analysis is performed using modular MATLAB ${ }^{\circledR}$ codes for the ISS ECLSS's constituent subsystems, assemblies, and components. The construction of a MATLAB ${ }^{\circledR}$ model for the ECLSS is of interest because it opens a path toward developing more complex transient models of ISS systems. In addition, this could be a starting point for physical systems simulation and investigation of ECLSS functional architectures in varied mission contexts and across multiple operational scenarios.
Exergy analysis presents a unique means of integrating system physics across a diverse set of platforms. Here this approach is demonstrated for the ARS portion of the ECLSS.

\section{METHODOLOGY}

In the 1998 configuration the ISS ECLSS may be divided into five subsystems as shown by Figure 1 which may then be further divided into assemblies and components for analysis. The overall system can be seen as a single master control volume that is unpacked into smaller control volumes with increasing detail at each subsystem, assembly, and component level. For each 
individual component in the ECLSS, a zero-dimensional assumption was made with the component taken as the control volume and a general exergy balance was derived. The general exergy balance is given in Equation 1a. For the current work, most components were treated as open flow systems in steady state. In this context, solving for exergy destruction in rate basis yields Equation 1b. In these equations, exergy is represented as $X$ and flow exergy is represented as $\psi$.

$$
\begin{aligned}
& \quad \frac{d X}{d t}=\sum_{i}\left(1-\frac{T_{0}}{T_{i}}\right) \dot{Q}_{i}+\left(\dot{W}_{\text {in }}-P_{0} \frac{d V}{d t}-\dot{W}_{\text {out }}\right)+ \\
& \sum_{i} \dot{m} \psi_{\text {in }}-\sum_{i} \dot{m} \psi_{\text {out }}-\dot{X}_{\text {des }} \\
& \quad \dot{X}_{\text {des }}=\sum_{i}\left(1-\frac{T_{0}}{T_{i}}\right) \dot{Q}_{i}+\left(\dot{W}_{\text {in }}-\dot{W}_{\text {out }}\right)+\sum_{i} \dot{m} \psi_{\text {in }}- \\
& \sum_{i} \dot{m} \psi_{\text {out }}
\end{aligned}
$$

To calculate the net exergy destruction rate for a subsystem, the exergy destruction rates of its constituent parts are summed, as shown in Equation 2. This summative approach allows the integral parts of the ECLSS to be integrated to yield an overall system exergy efficiency estimate.

$$
\dot{X}_{\text {des,subsystem }}=\sum \dot{X}_{\text {des,components }}
$$

There are multiple ways to define exergy efficiency. One way is by comparing the exergy destroyed by a component to the work that is put into the component as given in Equation 3a. The main advantage of this definition is that it is easily applicable to subsystems receiving power input as a whole. Another definition compares exergy transfer to the reversible work limit, which is the maximum exergy transfer if there is no exergy destruction (i.e. no irreversibility) in the component as given in Equation $3 b$. The main advantage of this latter definition is that exergy efficiency values can be calculated for components such as valves and heat exchangers where no power input is present. Supplied power is defined as a positive value.

$$
\begin{aligned}
& \varepsilon=1-\frac{\dot{X}_{\text {des }}}{\dot{W}_{\text {input }}} \\
& \varepsilon=\frac{\dot{W}_{\text {rev }}}{-\dot{W}_{\text {actual }}} \text { (work input) or } \varepsilon=\frac{\dot{W}_{\text {actual }}}{\dot{W}_{\text {rev }}} \text { (no input) }
\end{aligned}
$$

Exergy destruction cannot be calculated directly in rate basis for all components as shown above. This limitation is of particular note for components that operate cyclically. For such components, the total exergy destruction is calculated over a full cycle and time averaged in order to convert it to rate basis. The sorbent beds within the CDRA are outlined below as one

\begin{tabular}{|c|c|}
\hline Subsystem & Power Demand $(\mathrm{kW})$ \\
\hline ARS (without OGA) & 0.742 \\
\hline OGA (ARS component) & 1.660 \\
\hline Atmospheric Control and Supply & 0.088 \\
\hline Temperature and Humidity Control & 0.847 \\
\hline Water Recovery and Management & 0.527 \\
\hline Waste Management & 0.730 \\
\hline ECLSS Total & 4.594 \\
\hline
\end{tabular}
example of a cyclically operating component.

Table 1 lists the power consumption of each subsystem. Because the OGA accounts for a large portion of the total system exergy destruction, it is analyzed in greater detail.
Table 1. Power demand of each ECLS subsystem and the OGA.

\section{The Oxygen Generation Assembly}

The OGA is a vital part of the ECLSS because it generates oxygen for the crew to breathe. A simplified schematic of this assembly is provided by Figure 2. Relevant mass flow rates for the OGA are summarized in Table 2. The electrolyzer generates oxygen via water electrolysis to yield molecular hydrogen and oxygen. Because this reaction requires a large magnitude power demand relative to the entire ECLSS (approximately $1.5 \mathrm{~kW}$ of the $4.6 \mathrm{~kW}$ consumed by the system), varying parameters, properties, and the configuration of the electrolyzer could potentially have a large impact on the total system exergy destruction. The OGA's PEM electrolyzer was assumed to be insulated in order to simplify analysis. The power necessary to operate the electrolyzer was calculated by multiplying the voltage by the current through the electrolyzer. The electrolyzer voltage is a summation of the Nernst potential, the activation overpotential, ohmic overpotential, and concentration overpotential. The Nernst potential is the thermodynamic ideal at zero current on the voltage current curve. It is a function of the electrolyzer operating temperature. The activation overpotential is the potential needed to drive the electrolysis reaction and is a function of the exchange current densities at the anode and cathode. The ohmic overpotential is the potential added by resistance inside the electrolyzer. Membrane resistance and interfacial resistance are the main contributors to ohmic overpotential. The concentration overpotential is caused by transport limits that are not expected to be reached in this case and is therefore ignored. From these overpotentials, four parameters that were directly affected by type of material were chosen to be studied: exchange current density, membrane thickness, interfacial ohmic resistance, and membrane conductivity. Values were chosen from literature, and estimated from ranges if common values could not be identified [3,4,8-10].

Table 2. Mass flow rates in the OGA.

\begin{tabular}{|l|c|c|}
\hline \multicolumn{1}{|c|}{ Parameter } & \multicolumn{2}{c|}{ Mass Flow Rate } \\
\hline Water circulation in the loop & $254 \mathrm{~kg} /$ hour & $0.0029 \mathrm{~kg} / \mathrm{s}$ \\
\hline Oxygen produced & $2.75 \mathrm{~kg} /$ day & $7.64 \times 10^{-4} \mathrm{~kg} / \mathrm{s}$ \\
\hline Hydrogen produced & $0.34 \mathrm{~kg} /$ day & $9.44 \times 10^{-5} \mathrm{~kg} / \mathrm{s}$ \\
\hline
\end{tabular}




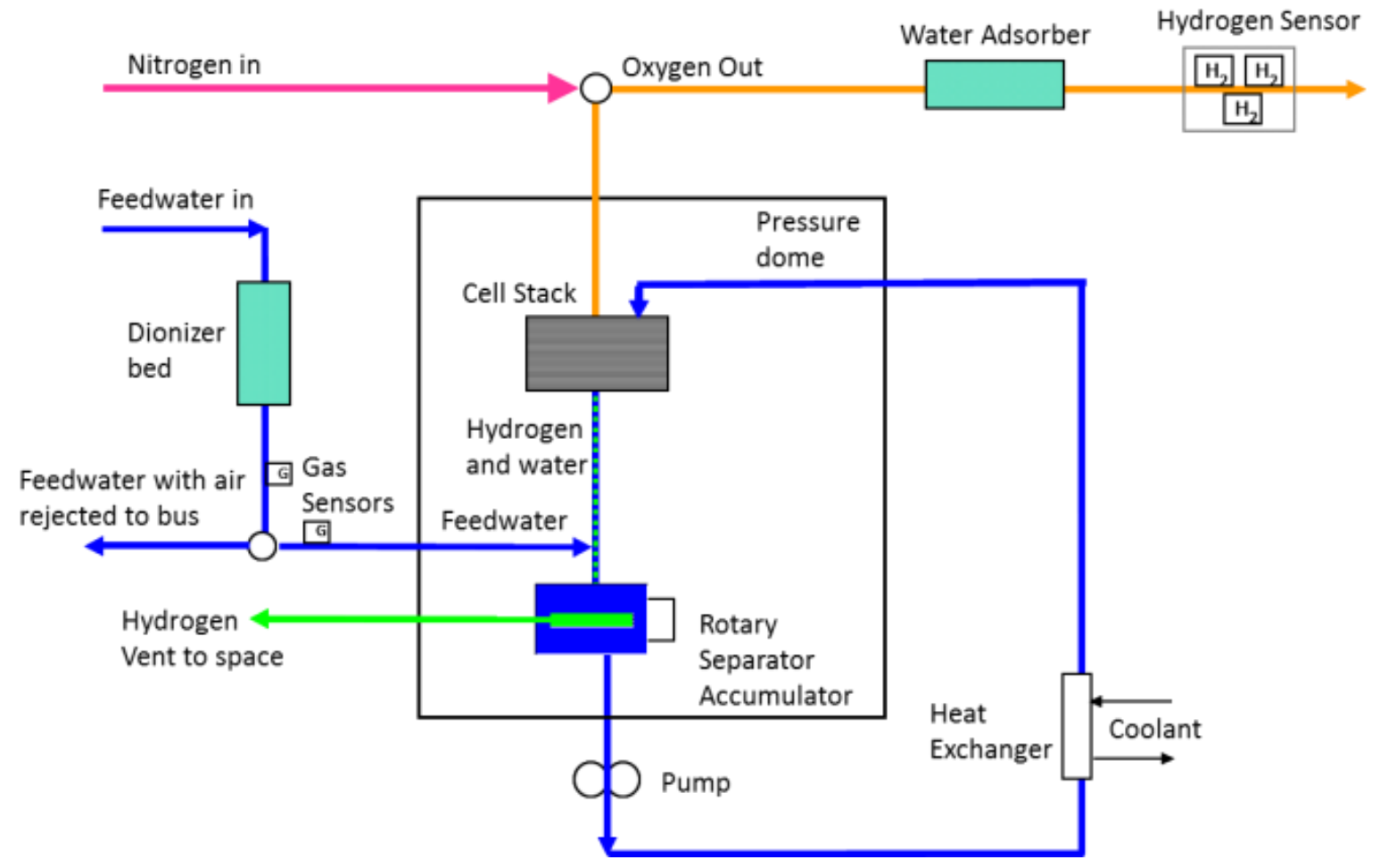

Figure 2. A simplified Oxygen Generation Assembly schematic.

The electrolyzer voltage was calculated as a function of current density and operating conditions according to Equation 4 . It is noted that overpotentials are represented by the symbol $\eta$. A flowchart of the OGA exergy destruction calculation is given in Figure 3. It is noted that in this schematic $V$ represents voltage and $i$ represents current density. As previously stated, the concentration overpotentials have been ignored because the electrolyzer is not expected to operate in conditions where the concentration overpotential would significantly contribute to the overall cell potential.

$$
V(T, p, i)=E_{0}(T, p)+\eta_{\text {act }}(i)+\eta_{\text {ohmic }}(i)
$$

Exergy balance and efficiency for the OGA after applying all assumptions are given in equations $5 \mathrm{a}$ and $5 \mathrm{~b}$.

$$
\begin{gathered}
\dot{X}_{\text {des }, \text { OGA }}=\dot{W}_{\text {elec }}+\dot{m}_{\mathrm{H}_{2} \text { O, reacted }}\left(h_{\mathrm{H}_{2} \mathrm{O}, \text { in }}-T_{0} S_{\mathrm{H}_{2} \mathrm{O}, \text { in }}\right)- \\
{\left[\dot{m}_{\mathrm{H}_{2}, \text { out }}\left(h_{\mathrm{H}_{2}, \text { out }}-T_{0} S_{\mathrm{H}_{2}, \text { out }}\right)+\dot{m}_{\mathrm{O}_{2}, \text { out }}\left(h_{\mathrm{O}_{2}, \text { out }}-T_{0} S_{\mathrm{O}_{2}, \text { out }}\right)\right]}
\end{gathered}
$$

$$
\varepsilon_{O G A}=\dot{m}_{H_{2} \mathrm{O} \text {, reacted }}\left(h_{\mathrm{H}_{2} \mathrm{O}, \text { in }}-T_{0} S_{\mathrm{H}_{2} \mathrm{O}, \text { in }}\right)-
$$$$
\left[\dot{m}_{\mathrm{H}_{2}, \text { out }}\left(h_{\mathrm{H}_{2}, \text { out }}-T_{0} s_{\mathrm{H}_{2}, \text { out }}\right)+\dot{m}_{\mathrm{O}_{2}, \text { out }}\left(h_{\mathrm{O}_{2}, \text { out }}-\right.\right.
$$$$
\left.\left.T_{0} s_{O_{2}, \text { out }}\right)\right] /-\dot{W}_{\text {elec }}
$$

In addition to exergy analysis conducted on the OGA electrolyzer, calculations were also made using other values of membrane and exchange current parameters based on material properties to determine their effects on the electrolyzer's voltage-current curve.

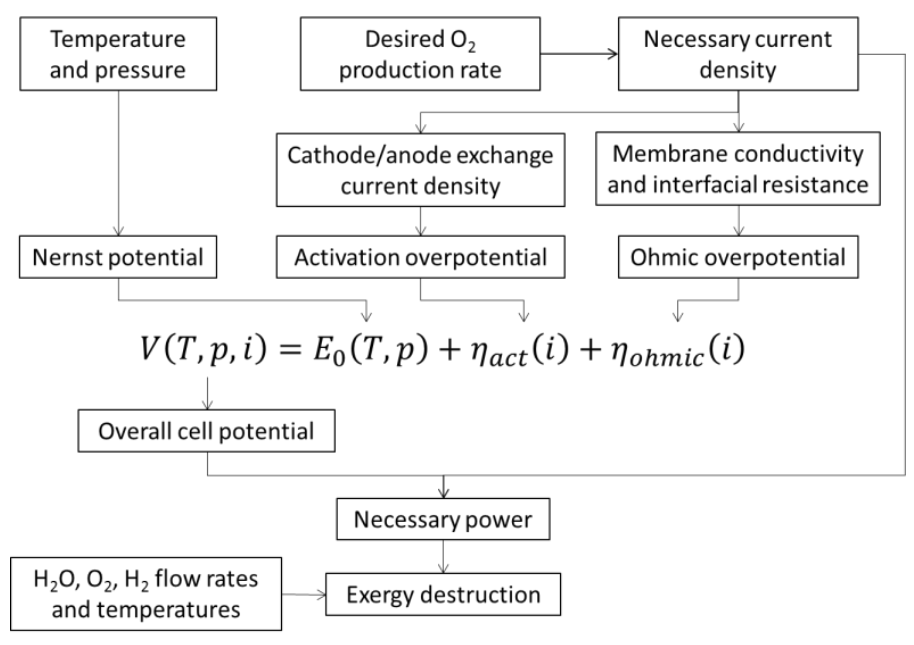

Figure 3. Flowchart for calculating power consumption and exergy destruction in the OGA electrolyzer.

\section{The Carbon Dioxide Removal Assembly}

The CDRA, shown schematically by Figure 4, is an assembly within the ARS that removes $\mathrm{CO}_{2}$ from the ISS cabin atmosphere. The components within the CDRA that are analyzed are the blower, precooler, and the sorbent bed. The CDRA also contains cyclically operating components in the form of packed 


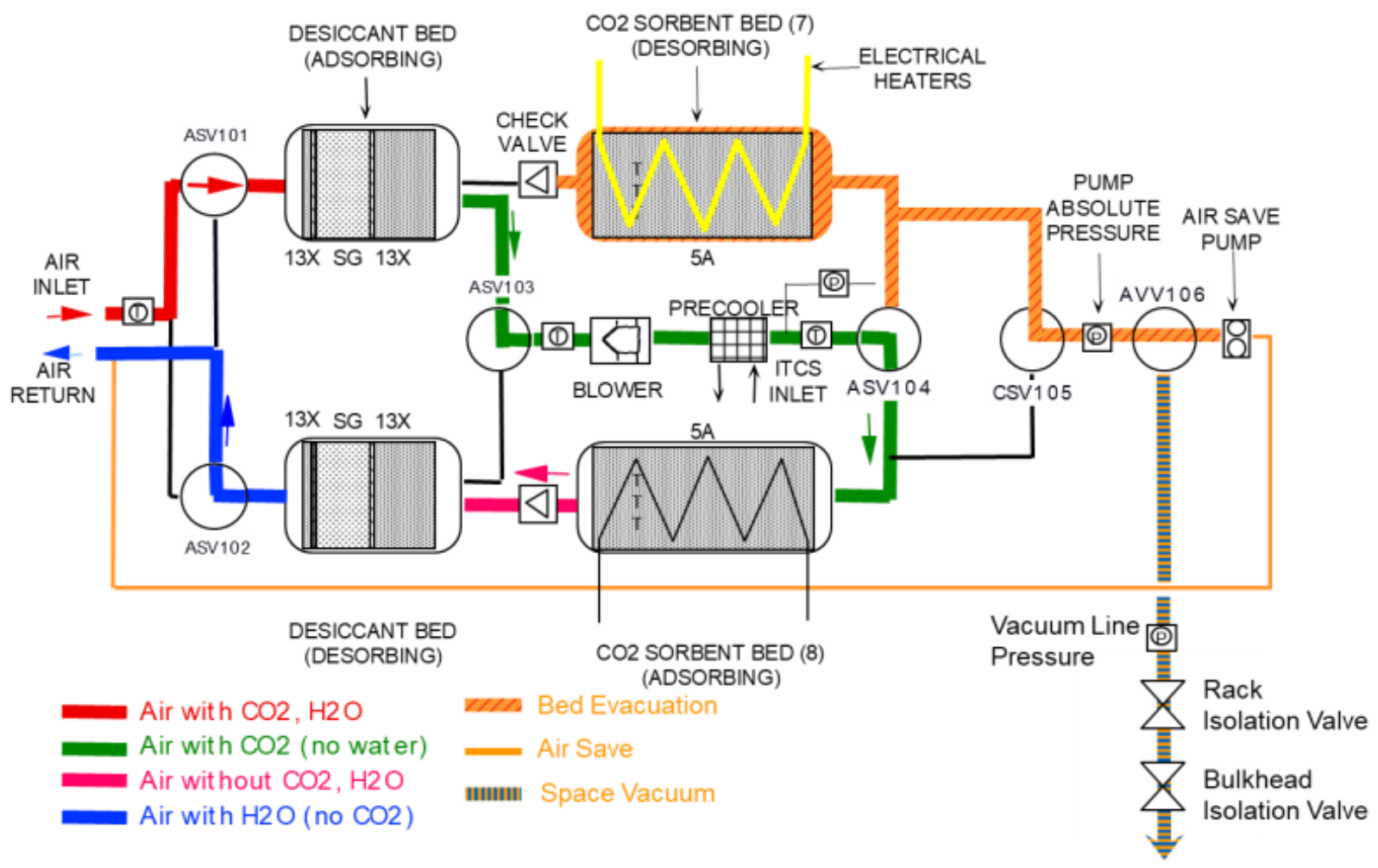

Overboard Space Vacuum

Figure 4. A simplified Carbon Dioxide Removal Assembly schematic.

desiccant and sorbent beds. Exergy destruction for the process of venting $\mathrm{CO}_{2}$ to space is also analyzed. The CDRA illustrates applications of the exergy balance equations for different common types of components such as fans and heat exchangers within the ECLSS. The total exergy destruction of the CDRA is given in Equation 6a, and the exergy efficiency is given in Equation $6 \mathrm{~b}$.

$$
\begin{gathered}
\dot{X}_{\text {des }, C D R A}=\dot{X}_{d e s, \text { precooler }}+\dot{X}_{\text {des, blower }}+ \\
\dot{X}_{\text {des,sorbent bed }}+\dot{X}_{\text {des }, \mathrm{CO}_{2} \text { vent }} \\
\varepsilon=1-\frac{\dot{X}_{\text {des }, C D R A}}{\dot{W}_{\text {input }, C D R A}}
\end{gathered}
$$

The blower is an example of a component with a power input and net exergy change in the stream flowing through the component. Exergy balances for fans and most other components with a power input are similar to the blower in this example. Using the reversible work limit formulation, the reversible work limit is calculated in Equation 7a. Exergy destruction and efficiency are calculated in Equations $7 \mathrm{~b}$ and $7 \mathrm{c}$, noting that the power input is a positive value.

$$
\begin{array}{r}
\dot{W}_{\text {rev,blower }}=-\left(1-\frac{T_{0}}{T_{\text {blower }}}\right) \dot{Q}_{\text {blower }}+\dot{m}_{\text {air }}\left[\left(h_{\text {air, in }}-\right.\right. \\
\left.\left.h_{\text {air,out }}\right)-T_{0}\left(s_{\text {air,in }}-s_{\text {air,out }}\right)\right]
\end{array}
$$

$$
\begin{aligned}
& \dot{X}_{\text {des,blower }}=\dot{W}_{\text {rev,blower }}+\dot{W}_{\text {actual,blower }} \\
& \varepsilon_{\text {blower }}=\frac{\dot{W}_{\text {rev,blower }}}{-\dot{W}_{\text {actual,blower }}}
\end{aligned}
$$

The precooler is an example of a heat exchanger type component in which exergy is transferred from a hot stream to a cool stream. The exergy destruction is the flow exergy that is lost by the hot stream that is not gained by the cool stream, as given in Equation 8a. The exergy efficiency is the flow exergy that is gained by the cool stream relative to the flow exergy that is lost by the hot stream, as given in Equation $8 \mathrm{~b}$.

$$
\begin{aligned}
& \dot{X}_{\text {des,precooler }}=\dot{m}_{\text {air }}\left[\left(h_{\text {air,in }}-h_{\text {air }, \text { out }}\right)-T_{0}\left(s_{\text {air }, \text { in }}-\right.\right. \\
& \left.\left.s_{\text {air,out }}\right)\right]+\dot{m}_{\text {coolant }}\left[\left(h_{\text {coolant,in }}-h_{\text {coolant,out }}\right)-\right. \\
& \left.T_{0}\left(s_{\text {coolant,in }}-s_{\text {coolant,out }}\right)\right] \\
& \varepsilon_{\text {precooler }}=
\end{aligned}
$$

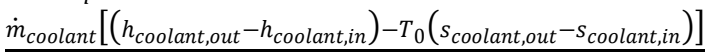

$$
\begin{aligned}
& \dot{m}_{\text {air }}\left[\left(h_{\text {air,in }}-h_{\text {air }, \text { out }}\right)-T_{0}\left(s_{\text {air }, \text { in }}-s_{\text {air }, \text { out }}\right)\right]
\end{aligned}
$$

Heating and cooling of the sorbent beds is an example of a process that cannot be modeled directly as a rate basis. In each full cycle, one of the sorbent beds is heated while the other is 
cooled in the first half cycle, and then one bed is cooled while the other is heated in the other half cycle [1]. As shown in Equations 9a-9c, for a sorbent bed, the full cycle is divided into half cycles, and the total exergy change of the bed, instead of specific flow exergy as described in the examples above, is calculated. Power is supplied to the sorbent bed only during heating. Therefore, the power input is time averaged over a full cycle as shown in Equation 9d. If the assumption is made that the sorbent beds are well insulated, heat loss terms can be neglected, simplifying the sorbent beds to exergy sinks. Equation 9e shows that this exergy sink mathematically has an exergy efficiency of zero.

$$
\begin{gathered}
\dot{X}_{\text {des,sorbent bed }}=\frac{X_{\text {des,heating }}+X_{\text {des,cooling }}}{t_{\text {cycle }}} \\
X_{\text {des,heating }}=\left(\dot{W}_{\text {heating }}\right)\left(t_{\text {heating }}\right)+\left(\left(H_{1}-H_{2}\right)-\right. \\
\left.\left.T_{1}-S_{2}\right)\right) \\
X_{\text {des,cooling }}=\left(\left(H_{2}-H_{1}\right)-T_{0}\left(S_{2}-S_{1}\right)\right) \\
\dot{X}_{\text {input,sorbent bed }}=\dot{W}_{\text {heating }}\left(\frac{t_{\text {heating }}}{t_{\text {cycle }}}\right) \\
\varepsilon_{\text {sorbent bed }}=1-\frac{\dot{X}_{\text {des,sorbent bed }}}{\dot{X}_{\text {input,sorbent bed }}}=0
\end{gathered}
$$

The CDRA vents $\mathrm{CO}_{2}$ removed from the cabin to space. In this case, internal energy is the obtainable work in the $\mathrm{CO}_{2}$ and the rate of venting is averaged over a full CDRA cycle as given in Equation 10a. Since the $\mathrm{CO}_{2}$ is permanently removed from the system, its exergy content is completely lost so the exergy efficiency is zero as given in Equation 10b.

$$
\begin{aligned}
& \dot{X}_{\text {des, } \mathrm{CO}_{2} \text { venting }}=\frac{m_{\mathrm{CO}_{2} u_{\mathrm{CO}_{2}}}}{t_{c y c l e}} \\
& \varepsilon_{\mathrm{CO}_{2} \text { venting }}=0
\end{aligned}
$$

\section{The Trace Contaminant Control Subassembly}

The Trace Contaminant Control Subassembly (TCCS) is a component within the ARS subsystem that removes volatile organic compounds (VOCs), carbon monoxide, and ammonia from the cabin atmosphere. The TCCS is comprised of two filter beds, a blower, a catalytic oxidizer, and a flow bypass. A simplified schematic of the TCCS is shown in Figure 5.

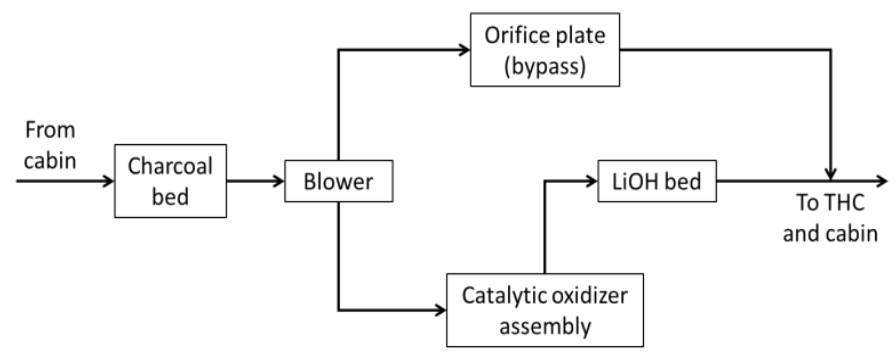

Figure 5. A simplified Trace Contaminant Control Subassembly schematic.
The charcoal and lithium hydroxide beds act as filters that trap and remove volatile organic compounds and acid gases from the process air stream. These beds act passively and do not require a power source, so exergy efficiency compares the exergy content of the flow leaving the bed to the exergy content of the flow entering the bed. The mass of chemical contaminants trapped by these beds is considered to be removed from the system. Equations 11a and 11b, respectively, show the exergy destruction and efficiency for the beds.

$$
\begin{gathered}
\dot{X}_{\text {des,bed }}=m_{\text {air }, \text { in }}\left(h_{\text {air }, \text { in }}-T_{0} s_{\text {air }, \text { in }}\right)-\left(\dot{m}_{\text {air }, \text { in }}-\right. \\
\left.\dot{m}_{\text {deposited }}\right)\left(h_{\text {air }, \text { out }}-T_{0} s_{\text {air }, \text { out }}\right) \\
\varepsilon_{\text {bed }}=\left(\dot{m}_{\text {air }, \text { in }}-\dot{m}_{\text {deposited }}\right)\left(h_{\text {air,out }}-T_{0} s_{\text {air }, \text { out }}\right) / \\
\dot{m}_{\text {air }, \text { in }}\left(h_{\text {air }, \text { in }}-T_{0} s_{\text {air }, \text { in }}\right)
\end{gathered}
$$

The TCCS blower is identical to the CDRA blower with the exception of small impeller design differences. Therefore, the exergy destruction and efficiency are calculated similarly to the CDRA blower as given in Equations $7 \mathrm{~b}$ and $7 \mathrm{c}$. The flowmeter is considered to be an exergy sink where only the power consumption is considered. The high temperature catalytic oxidizer (HTCO) heats the air to oxidize methane, carbon monoxide, and low molecular weight VOCs from the process air stream. Because it is a part in which power is supplied and some exergy is transferred to the airflow, exergy destruction and efficiency is also calculated similarly to the blower. The flow bypass is not analyzed because it is a part where no change in flow exergy occurs. The total exergy destruction of the TCCS is given in Equation 12.

$$
\begin{gathered}
X_{\text {des,TCCS }}=\dot{X}_{\text {des,charcoal bed }}+\dot{X}_{\text {des,flowmeter }}+ \\
\dot{X}_{\text {des,blower }}+\dot{X}_{\text {des,LiOH bed }}+\dot{X}_{\text {des }, \text { HTCO }}
\end{gathered}
$$

\section{The Major Constituent Analyzer}

The Major Constituent Analyzer (MCA), shown schematically by Figure 6 , is a component within the ARS that continuously monitors the cabin atmosphere's composition. The MCA draws a sample from the cabin atmosphere and analyzes the nitrogen, oxygen, $\mathrm{CO}_{2}$, methane, hydrogen, and water vapor concentrations.

Only three aspects of the MCA are analyzed because the time averaged magnitude of its exergy destruction is expected to be very small compared to the rest of the system. These parts are highlighted in Figure 6. The exergy destruction of the mass spectrometer is calculated similarly to other parts where power is supplied and there is some change in exergy content of the air flowing through. Here, it is assumed to be insulated, so the heat transfer term in Equation 7a is neglected, resulting in Equation 13. Otherwise, exergy destruction and efficiency calculations are done similarly to the blower in Equation 7.

$$
\begin{aligned}
& \dot{W}_{\text {rev,blower }}=\dot{m}_{\text {air }}\left[\left(h_{\text {air }, \text { in }}-h_{\text {air }, \text { out }}\right)-T_{\text {ref }}\left(s_{\text {air }, \text { in }}-\right.\right. \\
& \left.\left.s_{\text {air }, \text { out }}\right)\right]
\end{aligned}
$$

Exergy destruction and efficiency for the sample pump are also calculated similarly to Equations 7a-c. Finally, the MCA 
heater is treated as an exergy sink in which the power supplied is considered exergy destroyed and efficiency is zero. Therefore, the total exergy destruction of the MCA is calculated as given in Equation 14.

$$
X_{\text {des,MCA }}=\dot{X}_{\text {des,mass spec }}+\dot{X}_{\text {des,pump }}+\dot{X}_{\text {des,heater }}
$$

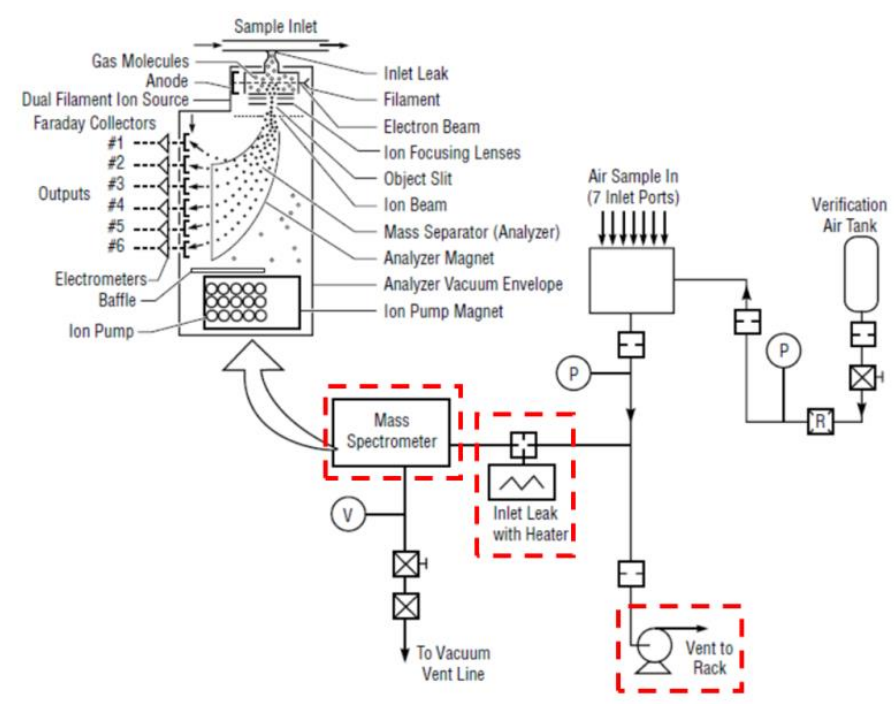

Figure 6. A simplified Major Constituent Analyzer schematic. Analyzed components are highlighted by red boxes. Base figure is adapted from [1].

\section{Implementation of the Exergy Equations}

The above exergy balances were implemented in a modular MATLAB $^{\circledR}$ code that calculates exergy destruction and efficiencies for the ECLSS components, subsystems, and the overall system. Component schematics and parameters such as temperature and flow rate through components were taken from literature [1]. Subject matter experts were consulted to clarify on components for which schematics and values were unclear or unavailable. From these exergy balances, exergy destruction rates and efficiencies were calculated. For the contribution of the OGA electrolyzer to the entire ECLS system, fixed values were assumed for all parameters.

\section{RESULTS AND DISCUSSION}

The results of the overall exergy assessment and details relating to the ARS with an emphasis on the OGA are provided by the following discussion. Areas for improving the OGA's performance are presented and discussed.

\section{Overall ECLSS Assessment}

The MATLAB ${ }^{\circledR}$ program calculated exergy destruction for ECLS subsystems and components. Exergy destruction and efficiency for the overall ECLSS and each of its subsystems is shown in Figure 7. These subsystems include the ARS, THC, WRM, ACS, and WM. The OGA was found to be the largest contributor with respect to the total exergy destruction rate of the subsystem. In addition, the OGA was found to have very low exergy efficiency, indicating that it is an exergy sink and most of the exergy that went into the electrolyzer was used to separate water into hydrogen and oxygen. Specifically, the exergy efficiency of the OGA was on the order of $10^{-4}$, or $0.01 \%$. This low performance may be attributed to operating the electrolyzer near cabin temperature, typically between $21^{\circ} \mathrm{C}$ and $27^{\circ} \mathrm{C}$, and the venting of hydrogen to space. Reducing the power consumption of the OGA electrolyzer would reduce exergy destruction and improve the overall efficiency of the ECLSS. Additionally, developing safe methods of utilizing hydrogen produced could also improve the exergy efficiency.

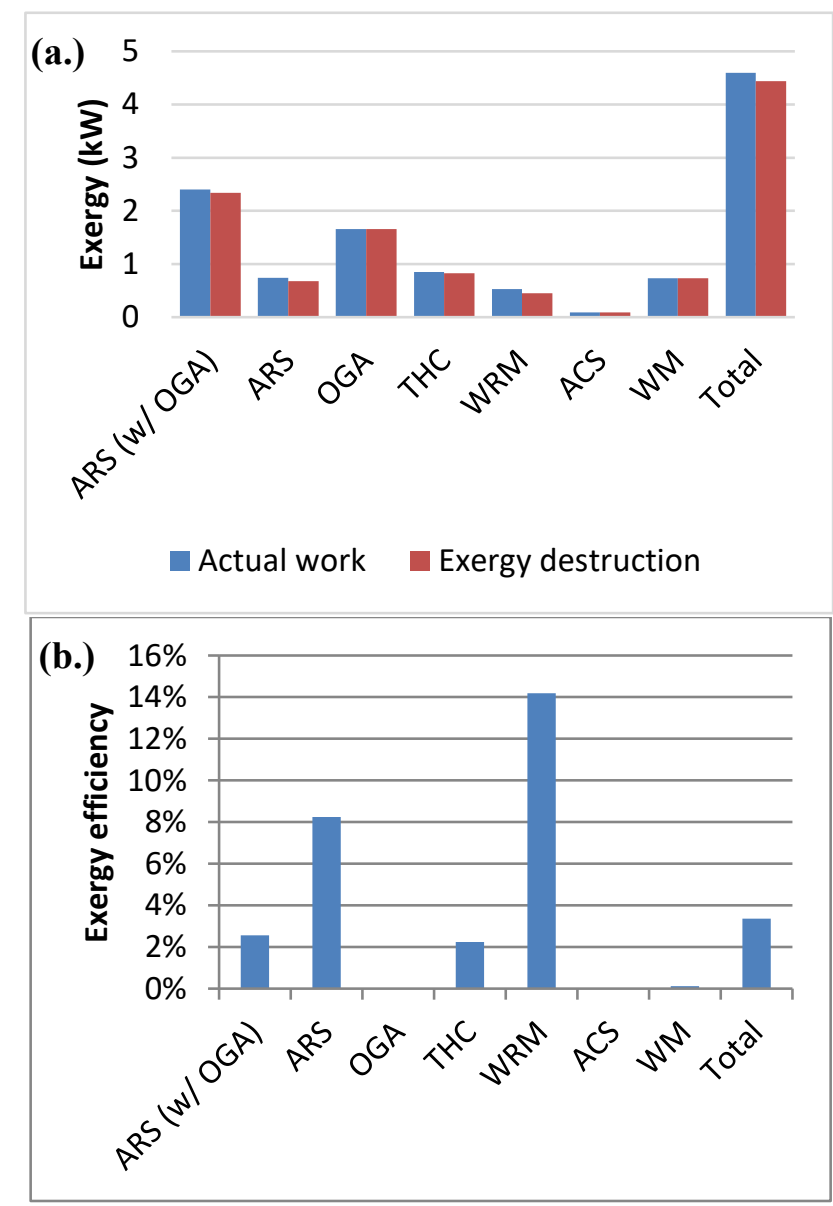

Figure 7. Exergy destruction and efficiency. (a) Total ECLSS exergy destruction and dominant subsystem sources; (b) Exergy efficiency of each subsystem in the ECLSS. The OGA, although part of the ARS, is displayed separately for comparison.

The remainder of the ARS, including components such as the CDRA, and the THC subsystem as a whole were found to be the next largest sources of exergy destruction. Exergy efficiency was found to be low for all subsystems, with the highest subsystem efficiency under $15 \%$. The low overall efficiency is explained by the function of the ECLSS, which maintains 
conditions and removes waste from the ISS habitat and crew through power consuming processes. This function is performed while keeping the system near the reference state of the ISS cabin. Because exergy efficiency is low in this case, targeting the reduction of power consumption by subsystems and their components would best reduce the exergy destruction of the overall system.

\section{Detailed ARS Assessment}

The exergy analysis also considers individual components within each subsystem in the ECLSS. Figure 8 is an example where the ARS is divided into components. Other subsystems may be similarly divided into components, but results are not shown for brevity and because of similarity in exergy efficiency values. At the component level, low exergy efficiency is still common. The TCCS has relatively higher exergy efficiency with respect to the other components because it removes gaseous chemical contaminants from the cabin atmosphere and returns the purified air to the cabin. The MCA has low exergy destruction and efficiency because it takes in a small amount of air to analyze for data on atmospheric composition. There is little change in state for the analyzed sample and the system consumes a small power input.
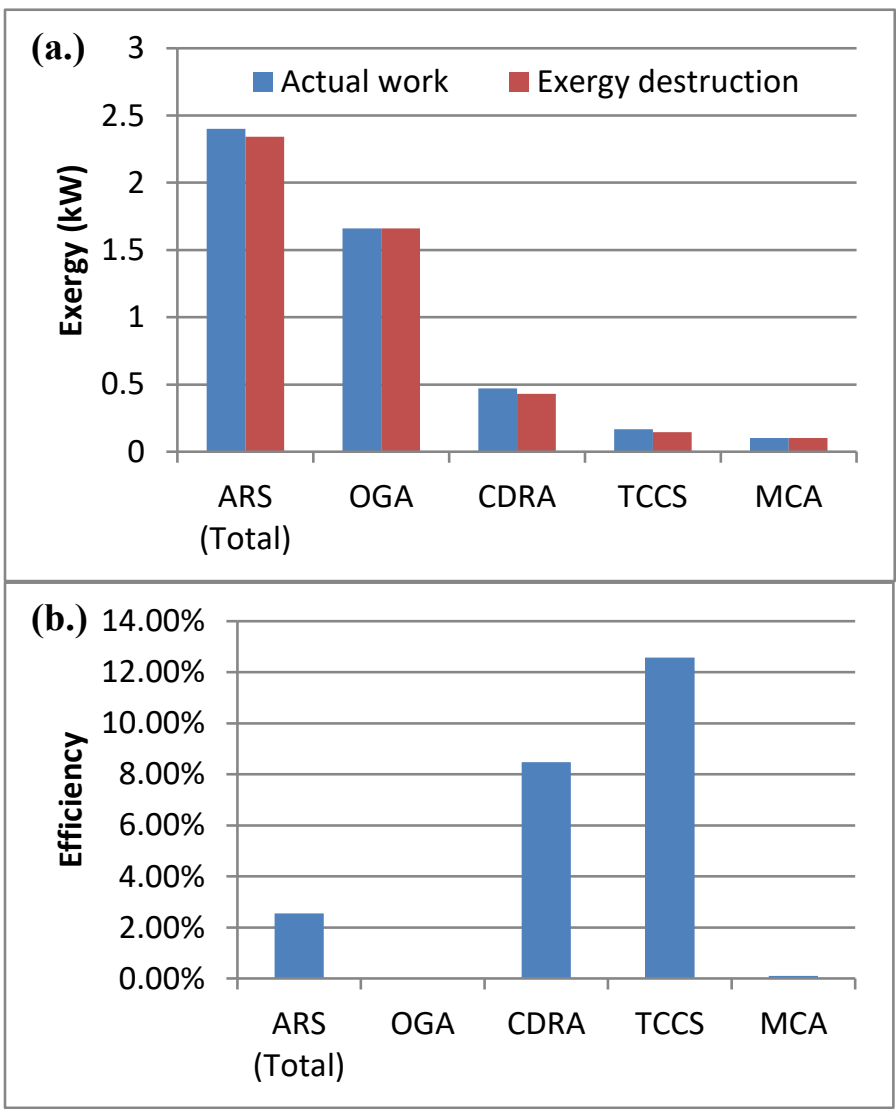

Figure 8. ARS exergy destruction and efficiency. (a) Total ARS exergy destruction and dominant sources; (b) Exergy efficiency of each component in the ARS.

\section{Improving OGA Electrolyzer Performance}

In addition to the exergy analysis, the effects of material properties on voltage-current curves were examined. From literature, a wide range of values can be found for these parameters in similar PEM electrolyzers [4,5,10]. Effects of varying these parameters are shown in Figure 9, with the blue lines representing the voltage current curves used in the exergy destruction calculations, and red lines representing alternate curves resulting from changing a parameter as described above the curve.
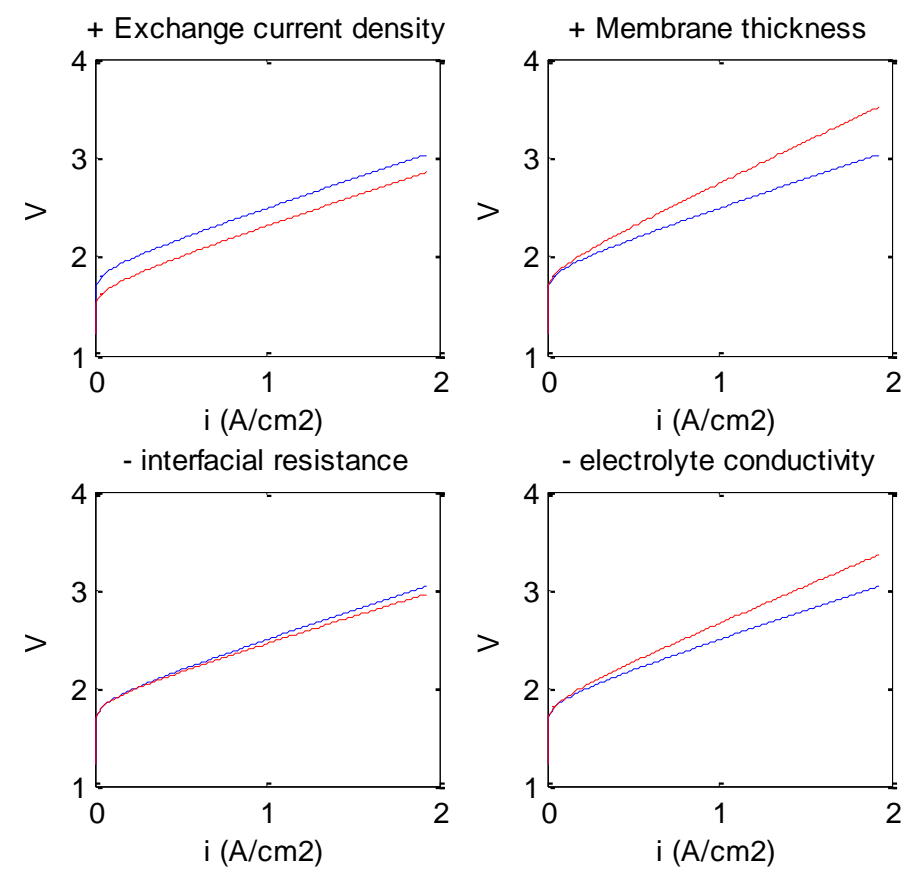

Figure 9. Effects of varying OGA electrolyzer parameters based on material properties. Blue lines represent the voltagecurrent curve generated using "default" parameters and red lines reflect the voltage-current curve generated using changed parameters.

A very wide range of values for exchange current density are quoted in the literature, varying by many orders of magnitude. Exchange current density is typically a function of anode and cathode materials. By increasing the exchange current density, voltage at the region of the voltage-current curve affected by the activation overpotential may be decreased significantly. Membrane thickness and interfacial resistance are properties of the membrane in a PEM electrolyzer. A thicker membrane increases voltage in the ohmic region of the voltage current curve, due to the additional membrane thickness increasing the resistance of the membrane. Less resistance at the interface is more desirable because the required voltage is decreased as a result. The last parameter examined is the conductivity of the electrolyte used in the electrolyzer. Electrolyte conductivity, like the membrane and interfacial 
properties, affects the ohmic region of the voltage-current curve. Values used for these parameters are given in Table 3.

Table 3. Parametric study parameters.

\begin{tabular}{|l|c|c|c|}
\hline \multicolumn{1}{|c|}{ Parameter } & Units & $\begin{array}{c}\text { Default } \\
\text { Value }\end{array}$ & $\begin{array}{c}\text { Changed } \\
\text { Value }\end{array}$ \\
\hline Anode exchange current density & $\mathrm{A} / \mathrm{cm}^{2}$ & $1 \times 10^{-9}$ & $1 \times 10^{-7}$ \\
\hline Cathode exchange current density & $\mathrm{A} / \mathrm{cm}^{2}$ & $1 \times 10^{-3}$ & $1 \times 10^{-2}$ \\
\hline Membrane thickness & $\mu \mathrm{m}$ & 100 & 150 \\
\hline Membrane conductivity & $\mathrm{S} / \mathrm{cm}$ & .02 & .015 \\
\hline Interfacial resistance & $\Omega$ & .05 & .01 \\
\hline
\end{tabular}

Additional studies on the effects of parameters such as the operating temperature and heat exchanger configurations of the OGA are underway to determine their effects on total exergy destruction and efficiency in the current system. From literature, it is expected that a higher operating temperature will decrease voltage in the voltage-current curve and exergy destruction, which increases exergy efficiency $[4,5,9,10]$.

\section{CONCLUSION}

The 1998 configuration of the ISS ECLSS, [1], was divided into subsystems, assemblies, and components for system-level exergy analysis. The analysis showed that the exergy efficiency of the ECLSS is generally very low. Therefore, reducing power consumption would likely best reduce total exergy destruction and improve overall efficiency. Because the OGA, even as a component, dominates the magnitude of total system exergy destruction with respect to other subsystems as a whole, it is a target for improvement in order to reduce total system exergy destruction and produce significant gains in the overall efficiency of the overall ECLSS. Additional parametric studies on operating parameters and component configurations of the OGA are underway to find ways to accomplish this improvement.

There are several opportunities for further application and expansion of the exergy analysis approach outlined above. First, the MATLAB ${ }^{\circledR}$ model was developed as a demonstration using values and 1998 configuration schematics [1]. The model can be updated to reflect the most recent ISS ECLSS configuration and adapted to analyze ECLSS architectures for future exploration missions. Second, the model relies upon assessment of performance under steady-state operation. Modifications to account for transient behavior of cyclically operating subsystems and components, such as the CDRA, could be incorporated. Finally, further investigation could be done to increase the level of detail in the analysis of each ECLSS subsystem and their constituent assemblies and components. Delving into these details could provide the opportunity for investigating ECLSS performance across multiple operational scenarios that are envisioned for future exploration mission architectures. Each of these areas present routes for using exergy analysis as a tool for studying ECLSS behavior within varied operational, temporal, and spatial contexts.

\section{NOMENCLATURE}

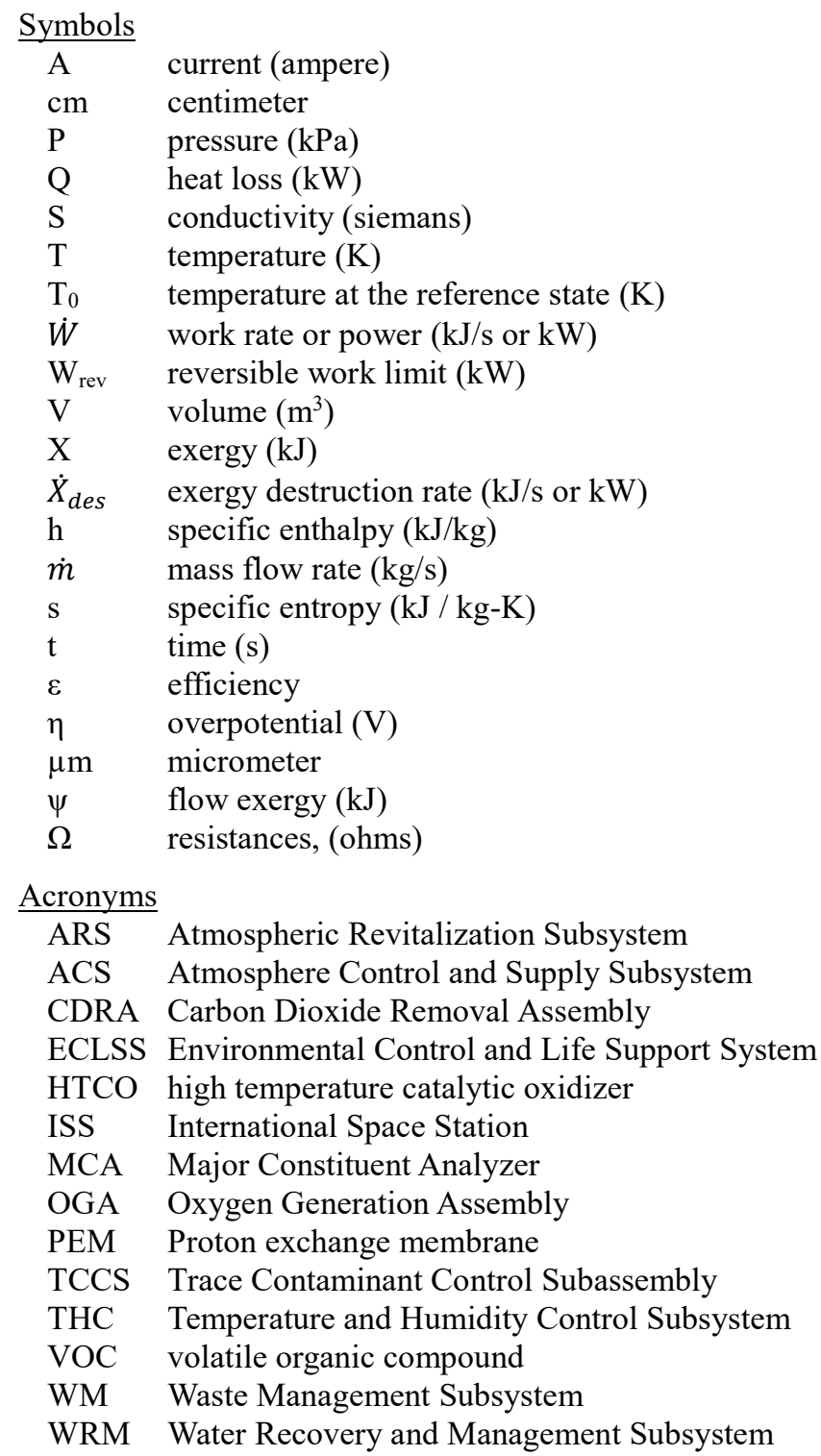

\section{ACKNOWLEDGMENTS}

Funding for this research from the NASA Systems Engineering Research Consortium is gratefully acknowledged. The authors thank Dr. Michael Watson of the NASA Marshall Space Flight Center for valuable discussions of exergy balance formulations.

\section{REFERENCES}

1. Wieland, P. O., Living Together in Space: The Design and Operation of the Life Support Systems on the International Space Station (NASA TM-98-206956 Volume 1), National Aeronautics and Space Administration, Marshall Space Flight Center, 1998.

2. Bejan A. Advanced Engineering Thermodynamics. 2nd Ed. New York: Wiley \& Sons; 1997. 
3. Badwal, S. P. S., Giddey, S., Ciacchi, F. T. (2006).

Hydrogen and oxygen generation with polymer electrolyte

membrane (PEM)-based electrolytic technology. Ionics, 12(1), 7-14. https://doi.org/10.1007/s11581-006-0002-x

4. Ni, M., Leung, M. K., Leung, D. Y. (2008). Energy and exergy analysis of hydrogen production by a proton exchange membrane (PEM) electrolyzer plant. Energy conversion and management, 49(10), 2748-2756.

https://doi.org/10.1016/j.enconman.2008.03.018

5. Choi, P., Bessarabov, D. G., \& Datta, R. (2004). A simple model for solid polymer electrolyte (SPE) water electrolysis. Solid State Ionics, 175(1-4), 535-539.

https://doi.org/10.1016/j.ssi.2004.01.076

6. Coker, R. F., Knox, J., Schunk, G., \& Gomez, C. (2015, July). Computer Simulation and Modeling of $\mathrm{CO}_{2}$ Removal Systems for Exploration. 45th International Conference on Environmental Systems.

7. Knox, J. C., \& Stanley, C. M. (2015, July). Optimization of the Carbon Dioxide Removal Assembly (CDRA-4EU) in Support of the International Space System and Advanced Exploration Systems. 45th International Conference on Environmental Systems.

8. Millet, P., Andolfatto, F., Durand, R. (1996). Design and performance of a solid polymer electrolyte water electrolyzer. International journal of hydrogen energy, 21(2), 87-93. https://doi.org/10.1016/0360-3199(95)00005-4

9. Awasthi, A., Scott, K., \& Basu, S. (2011). Dynamic modeling and simulation of a proton exchange membrane electrolyzer for hydrogen production. International journal of hydrogen energy, 36(22), 14779-14786. https://doi.org/10.1016/j.ijhydene.2011.03.045

10. García-Valverde, R., Espinosa, N., \& Urbina, A. (2012). Simple PEM water electrolyser model and experimental validation. International journal of hydrogen energy, 37(2), 1927-1938. https://doi.org/10.1016/j.ijhydene.2011.09.027 